\title{
Role of monitored anaesthesia care in peri-procedural stroke during unprotected transfemoral aortic valve replacement: A case report
}

\author{
hulya yilmaz $\mathrm{ak}^{1}$, Yasemin Ozsahin ${ }^{1}$, Kerem Erkalp ${ }^{1}$, and Ziya Salihoglu ${ }^{1}$ \\ ${ }^{1}$ Affiliation not available
}

January 12, 2021

\begin{abstract}
Abstract: Backgraound: Transcatheter aortic valve implantation (TAVI), with its improved valve technologies will also be an option for patients in the near future and improved operator experience. Cerebrovascular events are among the most feared complications of TAVI, since they cause high morbidity and mortality. Case: After the patient with EuroSCORE II $=8.6 \%$ was considered to be at high risk in terms of surgery, the decision to perform TAVI was taken. The valve (Medtronic 26 $\mathrm{mm}$ ) was successfully placed during the $110 \mathrm{~min}$ procedure. Blood loss was $140 \mathrm{~mL}$, no red blood cell (RBC) transfusion and catecholamines requirements were present, no VF (ventricular fibrillation) and cardiac tamponade were observed and post procedure left ventricular ejection fraction (LVEF) was $60 \%$. At the end of the procedure, the BIS value of the patient was 70 , regression in the Glasgow Coma Score $(\mathrm{GCS}=12)$, anisocoria in the pupils $(\mathrm{R}=2 \mathrm{~mm}<\mathrm{L}=4 \mathrm{~mm})$ and motor loss in the right arm $(3 / 5)$ and right leg (3/5) were detected. Modified Rankin scale (mRS) was evaluated as 4. Conclusions: The neurological complication rate of up to $80 \%$ during and in the days following the procedure, the long recovery period after embolism, the possibility of being a nursing patient and even the risk of death, remind us that the TAVI procedure and the sedation given during the procedure should never be underestimated. Keywords: Transcatheter aortic valve implantation, cerebral embolism, complications, neuroradiology, monitorized anaesthesia care, aort stenosis.
\end{abstract}

\section{Role of monitorized anesthesia care in peri-procedural stroke during unprotected transfemoral aortic valve replacement: A case report}

Authors:

Hulya Yılmaz Ak, Yasemin Ozsahin, Kerem Erkalp, Ziya Salihoglu

Istanbul University-Cerrahpasa Cardiology Institute Department of Anesthesiology and Reanimation, Istanbul, Turkey

Address for correspondence:

Hulya Yilmaz Ak, M.D., Assist Prof.

Department of Anesthesiology and Reanimation, Istanbul University-Cerrahpasa Cardiology Institute, Istanbul, Turkey

Phone: +90 5077855191

Fax: +902124592069

E-mail: hlyyilmazz@hotmail.com

Declarations of interest: none 


\section{Hosted file}

ENG_TAVI_case_report journal cardiovas.pdf available at https://authorea.com/users/388816/ articles/503545-role-of-monitored-anaesthesia-care-in-peri-procedural-stroke-duringunprotected-transfemoral-aortic-valve-replacement-a-case-report

\section{Hosted file}

FIGURE 1.pdf available at https://authorea.com/users/388816/articles/503545-role-ofmonitored-anaesthesia-care-in-peri-procedural-stroke-during-unprotected-transfemoralaortic-valve-replacement-a-case-report

\section{Hosted file}

FIGURE 2.pdf available at https://authorea.com/users/388816/articles/503545-role-ofmonitored-anaesthesia-care-in-peri-procedural-stroke-during-unprotected-transfemoralaortic-valve-replacement-a-case-report 